\title{
Alteration of Neutrophil Reactive Oxygen Species Production by Extracts of Devil's Claw (Harpagophytum)
}

\author{
Mbaki Muzila, ${ }^{1,2}$ Kimmo Rumpunen, ${ }^{1}$ Helen Wright, ${ }^{3}$ Helen Roberts, ${ }^{3}$ Melissa Grant, ${ }^{3}$ \\ Hilde Nybom, ${ }^{1}$ Jasna Sehic, ${ }^{1}$ Anders Ekholm, ${ }^{1}$ and Cecilia Widén ${ }^{4}$ \\ ${ }^{1}$ Department of Plant Breeding, Swedish University of Agricultural Sciences, Balsgård, Fjälkestadsvägen 459, \\ 29194 Kristianstad, Sweden \\ ${ }^{2}$ Biological Sciences, University of Botswana, Private Bag UB 00704, Gaborone, Botswana \\ ${ }^{3}$ School of Dentistry and MRC Centre for Immune Regulation, University of Birmingham, Saint Chads Queensway, \\ Birmingham B4 7ET, UK \\ ${ }^{4}$ School of Health and Society, University of Kristianstad, 29188 Kristianstad, Sweden \\ Correspondence should be addressed to Cecilia Widén; cecilia.widen@hkr.se
}

Received 11 February 2016; Accepted 29 May 2016

Academic Editor: Giuseppe Cirillo

Copyright (C) 2016 Mbaki Muzila et al. This is an open access article distributed under the Creative Commons Attribution License, which permits unrestricted use, distribution, and reproduction in any medium, provided the original work is properly cited.

Harpagophytum, Devil's Claw, is a genus of tuberiferous xerophytic plants native to southern Africa. Some of the taxa are appreciated for their medicinal effects and have been traditionally used to relieve symptoms of inflammation. The objectives of this pilot study were to investigate the antioxidant capacity and the content of total phenols, verbascoside, isoverbascoside, and selected iridoids, as well as to investigate the capacity of various Harpagophytum taxa in suppressing respiratory burst in terms of reactive oxygen species produced by human neutrophils challenged with phorbol myristate acetate (PMA), opsonised Staphylococcus aureus, and Fusobacterium nucleatum. Harpagophytum plants were classified into different taxa according to morphology, and DNA analysis was used to confirm the classification. A putative new variety of $H$. procumbens showed the highest degree of antioxidative capacity. Using PMA, three Harpagophytum taxa showed anti-inflammatory effects with regard to the PBS control. A putative hybrid between $H$. procumbens and $H$. zeyheri in contrast showed proinflammatory effect on the response of neutrophils to F. nucleatum in comparison with treatment with vehicle control. Harpagophytum taxa were biochemically very variable and the response in suppressing respiratory burst differed. Further studies with larger number of subjects are needed to corroborate anti-inflammatory effects of different taxa of Harpagophytum.

\section{Introduction}

Many diseases have an inflammatory pathogenesis and a large number of plant species have for centuries been utilized for their anti-inflammatory and healing effects. The medicinal tuberiferous xerophyte Devil's Claw (Harpagophytum) belongs to the family Pedaliaceae and is native to southern Africa [1]. This genus includes two species: Harpagophytum procumbens and $H$. zeyheri. There are also a few known subspecies of both species, as well as novel and hybrid taxa with less clear identity. Extracts made from the tubers of $H$. procumbens are known to relieve symptoms of inflammation and pain $[2,3]$ but there has been some argument about whether medicinal properties of $H$. zeyheri are sufficient for the acceptance of this species for use in anti-inflammatory preparations [4-6]. The pharmacological actions of Devil's Claw root tubers have been attributed to the presence of iridoid glycosides and verbascoside [4, 7, 8]. Studies have demonstrated anti-inflammatory properties such as inhibition of COX-2, inhibition of NF-kB activation, and downregulation of iNOS [9-11]. However, the effects of Devil's Claw have also been associated with the presence of other compounds such as flavonoids [11].

Neutrophil-mediated oxidant injury is a feature of many inflammatory diseases $[12,13]$. The initial response to infection is often mediated by neutrophils because of their rapid chemotactic response towards bacteria [14]. Neutrophils inhibit infection activity by ingestion of microorganisms, 
synthesis of reactive oxygen species (ROS), and release of cytokines. Neutrophils are important in both the innate and the acquired immune responses and microorganisms are recognized through receptor-mediated mechanisms, for example, by the antibody-antigen complex mediated $\mathrm{Fc}$ receptor $(\mathrm{FcR})$ and bacterial product mediated Toll-like receptors (TLR) $[15,16]$. These receptors represent specific, adaptive immune responses and nonspecific, innate immune responses, respectively, and activate intracellular signal transduction such as protein kinase C, MAPK cascades, and the $\mathrm{NADPH}$-oxidase enzyme complex [17]. The NADPH-oxidase enzyme complex produces ROS at the expense of NADPH. In resting cells from healthy donors little ROS is produced, limiting potential bystander damage to adjacent tissues. Upon stimulation ROS are produced in the local environment where they react rapidly with proximal molecules. In chronic inflammatory disease, such as severe gum disease (periodontitis), both resting and stimulated neutrophils are hyperactive [18]. Therapeutic strategies are continuously sought to decrease these characteristics and prevent excessive collateral tissue damage in infectious situations without preventing the primary infection fighting capacity. Neutrophils may therefore be used as a model to explore mechanisms and possible therapeutic modulation of inflammation.

The specific objective of this paper was (1) to identify and to select genetically diverse Harpagophytum plant material that adequately represents the pharmacological capability of the genus and (2) to determine the potential of root tuber ethanol extracts of various taxa to suppress the production of ROS in human neutrophils. We also investigated the antioxidant capacity and the content of ascorbate, verbascoside, isoverbascoside, major iridoids, and total phenols in the extracts.

\section{Materials and Methods}

2.1. DNA Studies and Plant Material Selection. Seed capsules (for taxonomic and DNA-based species determination) and secondary root tubers (for analysis of chemical content and in vitro studies) of 24 Harpagophytum accessions were sampled in Botswana (Table 1, Figure 1).

To select genetically diverse samples and to corroborate the taxonomical classification based on morphological characters DNA analyses were performed. One seed capsule was collected from each of the Harpagophytum accessions; seeds were germinated and one seedling per accession was used for extraction of DNA. DNA was extracted with the E.Z.N.A. ${ }^{\text {TM }}$ SP DNA mini kit (Omega Bio-Tek, Norcross, GA, USA). DNA quality was determined in $2 \%$ agarose gel. The DNA samples were analyzed with 2 inter-simple sequence repeat (ISSR) and 6 random amplified polymorphic DNA (RAPD) primers, using previously described methodology [19]. RAPD and ISSR bands were scored as present or absent, and a total of 107 polymorphic DNA bands were obtained. Based on the DNA studies 6 accessions representing 5 taxa were selected for use in the subsequent neutrophil and biochemical study: H. procumbens ssp. transvaalense (Accession 17; O1APT), a putative new variety of $H$. procumbens ssp. transvaalense

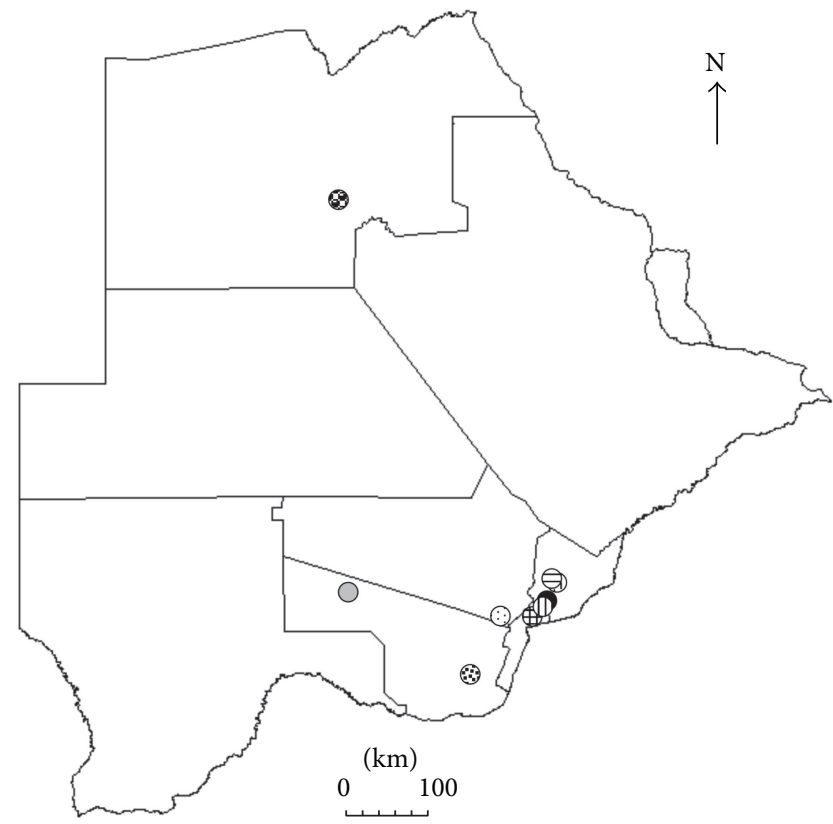

(11) Bela-Bela (Accessions 1-2)
$\bigcirc$ Kumakwane (Accessions 3-5)
Ө Leshibitse (Accession 6)
(1) Malotwana (Accessions 7-10)
Matlapaneng (Accessions 11-14)

9 Mmathethe (Accession 15)

Oodi (Accessions 16-18)

Sekoma (Accessions 19-20)

央 Tlokweng (Accessions 21-24)

FIGURE 1: Sampling sites in Botswana for accessions used in the DNA marker, biochemical and neutrophil studies.

(Accession 3; K1APN), H. zeyheri ssp. zeyheri (Accession 24; T1AZZ), and H. zeyheri ssp. sublobatum (Accession 14; MP3AZS) and two samples with unclear taxonomic identity but most likely interspecific hybrids between $H$. procumbens and H. zeyheri (Accession 16; O1APH and Accession 11; MP1APH) according to morphological characters of the tuber-bearing plants [20].

2.2. Root Sample Preparation. Samples of the root tubers were obtained by sectioning the specimen into halves, and the peel and pulp were separated, weighed, and freeze-dried at the Department of Plant Breeding, Balsgård, Swedish University of Agricultural Sciences. Vacuum was applied at $<0.2 \mathrm{mbar}$ and the condenser temperature was set at $-70^{\circ} \mathrm{C}$ during the freeze-drying process. The initial temperature of the sample tray was $-5^{\circ} \mathrm{C}$, and after $16 \mathrm{~h}$ a temperature gradient was applied from $-35^{\circ} \mathrm{C}$ to $10^{\circ} \mathrm{C}$. The temperature was then maintained at $10^{\circ} \mathrm{C}$ until the extracts were completely dry. The dry extracts were ground to a fine powder in a laboratory mill (Yellow line, A10, IKA-Werke, Staufen, Germany).

2.3. Extract Preparation. Extracts were made fresh before each experiment by adding $1 \mathrm{~mL}$ of $50 \%$ ethanol containing $0.05 \mathrm{M} \mathrm{H}_{3} \mathrm{PO}_{4}$ to $250 \mu \mathrm{g}$ (for in vitro studies) or $50 \mathrm{mg}$ (for biochemical studies) of finely ground Harpagophytum tuber powder. The extracts were kept in an ultrasonic bath for $15 \mathrm{~min}$ before centrifugation at $16000 \mathrm{~g}$ for $10 \mathrm{~min}$ and the 
TABLE 1: Accessions of Harpagophytum subjected to DNA analysis.

\begin{tabular}{|c|c|c|}
\hline Accession & Taxon & Location \\
\hline (1) B1AZZ & H. zeyheri ssp. zeyheri & Bela-Bela $\left(24^{\circ} 30.7^{\prime} \mathrm{S}, 26^{\circ} 2.27^{\prime} \mathrm{E}\right)$ introgression zone \\
\hline (2) $\mathrm{B} 1 \mathrm{APH}$ & $\begin{array}{l}\text { Putative hybrid (between } H \text {. procumbens and } H \text {. } \\
\text { zeyheri) }\end{array}$ & Bela-Bela $\left(24^{\circ} 30.7^{\prime} \mathrm{S}, 26^{\circ} 2.27^{\prime} \mathrm{E}\right)$ introgression zone \\
\hline (3) $\mathrm{K}_{1 \mathrm{APN}}^{*}$ & $\begin{array}{l}\text { Putative new variety of } H \text {. procumbens ssp. } \\
\text { transvaalense }\end{array}$ & Kumakwane $\left(24^{\circ} 37.9^{\prime} \mathrm{S}, 25^{\circ} 41.1^{\prime} \mathrm{E}\right)$ introgression zone \\
\hline (4) $\mathrm{K} 1 \mathrm{APH}$ & $\begin{array}{l}\text { Putative hybrid (between } H \text {. procumbens and } H \text {. } \\
\text { zeyheri) }\end{array}$ & Kumakwane $\left(24^{\circ} 37.9^{\prime} \mathrm{S}, 25^{\circ} 41.1^{\prime} \mathrm{E}\right)$ introgression zone \\
\hline (5) K1AZZ & H. zeyheri ssp. zeyheri & Kumakwane $\left(24^{\circ} 37.9^{\prime} \mathrm{S}, 25^{\circ} 41.1^{\prime} \mathrm{E}\right)$ introgression zone \\
\hline (6) L1APT & H. procumbens ssp. transvaalense & Leshibitse $\left(24^{\circ} 16.9^{\prime} \mathrm{S}, 26^{\circ} 9.41^{\prime} \mathrm{E}\right)$ introgression zone \\
\hline (7) ML1APN & $\begin{array}{l}\text { Putative new variety of } H \text {. procumbens ssp. } \\
\text { transvaalense }\end{array}$ & Malotwana $\left(24^{\circ} 17.5^{\prime} \mathrm{S}, 26^{\circ} 09.27^{\prime} \mathrm{E}\right)$ introgression zone \\
\hline (8) ML1BPN & $\begin{array}{l}\text { Putative new variety of } H \text {. procumbens ssp. } \\
\text { transvaalense }\end{array}$ & Malotwana $\left(24^{\circ} 17.5^{\prime} \mathrm{S}, 26^{\circ} 09.27^{\prime} \mathrm{E}\right)$ introgression zone \\
\hline (9) ML2APN & $\begin{array}{l}\text { Putative new variety of } H \text {. procumbens ssp. } \\
\text { transvaalense }\end{array}$ & Malotwana $\left(24^{\circ} 17.5^{\prime} \mathrm{S}, 26^{\circ} 09.27^{\prime} \mathrm{E}\right)$ introgression zone \\
\hline (10) ML3APN & $\begin{array}{l}\text { Putative new variety of } H \text {. procumbens ssp. } \\
\text { transvaalense }\end{array}$ & Malotwana $\left(24^{\circ} 17.5^{\prime} \mathrm{S}, 26^{\circ} 09.27^{\prime} \mathrm{E}\right)$ introgression zone \\
\hline (11) $\mathrm{MP}_{1 \mathrm{APH}}{ }^{*}$ & $\begin{array}{l}\text { Putative hybrid (between } H \text {. procumbens and } H \text {. } \\
\text { zeyheri) }\end{array}$ & $\begin{array}{l}\text { Matlapaneng }\left(19^{\circ} 55.4^{\prime} \mathrm{S}, 23^{\circ} 32.9^{\prime} \mathrm{E}\right) \text { H. zeyheri ssp. } \\
\text { sublobatum allopatric zone }\end{array}$ \\
\hline (12) MP1AZS & H. zeyheri ssp. sublobatum & $\begin{array}{l}\text { Matlapaneng }\left(19^{\circ} 55.4^{\prime} \mathrm{S}, 23^{\circ} 32.9^{\prime} \mathrm{E}\right) \mathrm{H} \text {. zeyheri ssp. } \\
\text { sublobatum allopatric zone }\end{array}$ \\
\hline (13) MP2AZS & H. zeyheri ssp. sublobatum & $\begin{array}{l}\text { Matlapaneng }\left(19^{\circ} 55.4^{\prime} \mathrm{S}, 23^{\circ} 32.9^{\prime} \mathrm{E}\right) \mathrm{H} \text {. zeyheri ssp. } \\
\text { sublobatum allopatric zone }\end{array}$ \\
\hline (14) MP3AZS* & H. zeyheri ssp. sublobatum & $\begin{array}{l}\text { Matlapaneng }\left(19^{\circ} 55.4^{\prime} \mathrm{S}, 23^{\circ} 32.9^{\prime} \mathrm{E}\right) \mathrm{H} \text {. zeyheri ssp. } \\
\text { sublobatum allopatric zone }\end{array}$ \\
\hline (15) MT1APT & H. procumbens ssp. transvaalense & $\begin{array}{l}\text { Mmathethe H. procumbens ssp. transvaalense allopatric } \\
\text { zone }\end{array}$ \\
\hline (16) $\mathrm{O}_{1 \mathrm{APH}}{ }^{*}$ & $\begin{array}{l}\text { Putative hybrid (between } H \text {. procumbens and } H \text {. } \\
\text { zeyheri) }\end{array}$ & Oodi $\left(24^{\circ} 28.1^{\prime} \mathrm{S}, 26^{\circ} 2.83^{\prime} \mathrm{E}\right)$ introgression zone \\
\hline (17) $\mathrm{O} 1 \mathrm{APT}^{*}$ & H. procumbens ssp. transvaalense & Oodi $\left(24^{\circ} 28.1^{\prime} \mathrm{S}, 26^{\circ} 2.83^{\prime} \mathrm{E}\right)$ introgression zone \\
\hline (18) O2APT & H. procumbens ssp. transvaalense & Oodi $\left(24^{\circ} 28.1^{\prime} \mathrm{S}, 26^{\circ} 2.83^{\prime} \mathrm{E}\right)$ introgression zone \\
\hline (19) S1APP & H. procumbens ssp. procumbens & $\begin{array}{l}\text { Sekoma }\left(24^{\circ} 24.8^{\prime} \mathrm{S}, 23^{\circ} 47.8^{\prime} \mathrm{E}\right) H . \text { procumbens ssp. } \\
\text { procumbens allopatric zone }\end{array}$ \\
\hline (20) S2APP & H. procumbens ssp. procumbens & $\begin{array}{l}\text { Sekoma }\left(24^{\circ} 24.8^{\prime} \mathrm{S}, 23^{\circ} 47.8^{\prime} \mathrm{E}\right) \mathrm{H} \text {. procumbens ssp. } \\
\text { procumbens allopatric zone }\end{array}$ \\
\hline (21) T1APT & H. procumbens ssp. transvaalense & Tlokweng $\left(24^{\circ} 37.8^{\prime} \mathrm{S}, 25^{\circ} 59.1^{\prime} \mathrm{E}\right)$ introgression zone \\
\hline (22) T1BPT & H. procumbens ssp. transvaalense & Tlokweng $\left(24^{\circ} 37.8^{\prime} \mathrm{S}, 25^{\circ} 59.1^{\prime} \mathrm{E}\right)$ introgression zone \\
\hline (23) T2APT & H. procumbens ssp. transvaalense & Tlokweng $\left(24^{\circ} 37.8^{\prime} \mathrm{S}, 25^{\circ} 59.1^{\prime} \mathrm{E}\right)$ introgression zone \\
\hline (24) T1AZZ* & H. zeyheri ssp. zeyheri & Tlokweng $\left(24^{\circ} 37.8^{\prime} \mathrm{S}, 25^{\circ} 59.1^{\prime} \mathrm{E}\right)$ introgression zone \\
\hline
\end{tabular}

* Accessions used in the neutrophil and biochemical study.

supernatant was collected. This resulted in a $100 \%$ stock with a concentration of $250 \mu \mathrm{g} / \mathrm{mL}$. This stock was then diluted $(\mathrm{v} / \mathrm{v})$ with phosphate-buffered saline (PBS) to produce final concentrations of $50 \%, 10 \%$, and $5 \%$.

2.4. Determination of Total Phenolics. To measure the total phenolic content according to the Folin-Ciocalteu method [21] the sample was mixed with Folin-Ciocalteu reagent (Merck, Darmstadt, Germany), $\mathrm{H}_{2} \mathrm{O}$, and $15 \% \mathrm{Na}_{2} \mathrm{CO}_{3}$ and the absorbance measured at $765 \mathrm{~nm}$ after $1 \mathrm{~h}$ incubation at room temperature. Gallic acid was used as a standard and the total content of phenols was expressed as mg gallic acid equivalents (GAE) per g dry weight (dw). For comparison, total phenolic content was analyzed also in commercially obtained, external standards of 8-O-p-coumaroyl-harpagide, harpagoside, and verbascoside.

2.5. Determination of Ferric Reducing Ability of Plasma. The ferric reducing ability of plasma (FRAP) of the extracts was measured according to the method developed by Benzie and Strain [22] but modified to fit a 96-well format [23]. The different extracts were diluted 20-100-fold. Ten $\mu \mathrm{L}$ of these extracts was incubated at $37^{\circ} \mathrm{C}$ and then mixed with $260 \mu \mathrm{L}$ of ferric-TPTZ reagent (prepared by mixing $300 \mathrm{mM}$ acetate 
buffer, $\mathrm{pH}$ 3.6; $10 \mathrm{mM}$ of 2,4,6-tripyridyl-s-triazine in $40 \mathrm{mM}$ $\mathrm{HCl}$; and $20 \mathrm{mM} \mathrm{FeCl}_{3}$ in the ratio of $4: 1: 1$; the solution was kept at $37^{\circ} \mathrm{C}$ ). The absorbance was measured at $595 \mathrm{~nm}$ after 4 min on a plate reader (Sunrise, Tecan Nordic AB, Sweden). $\mathrm{Fe}^{2+}$ was used as a standard and L-ascorbic acid was used as a control where one mole of ascorbic acid corresponds approximately to two moles of FRAP (we obtained the value 2.09).

2.6. HPLC Analysis of Ascorbate, Verbascoside, Isoverbascoside, and Iridoids. For ascorbate analysis samples were placed in ultrasonic bath for $10 \mathrm{~min}$ and centrifuged for $10 \mathrm{~min}$ at $2000 \mathrm{~g}$ (Beckham, USA). The supernatant was filtered with a syringe particle filter (glass/nylon $0.45 \mu \mathrm{m}, 30 \mathrm{~mm}$ Cameo, Sorbent AB, Sweden) directly into an HPLC-vial. The analysis was made on a Shimadzu HPLC system consisting of a communication bus module (SCL 10A-VP) and a pump (LC 10AD) using an ACE $(5 \mu \mathrm{m})$ for separation. For detection a variable SPD-10A UV-VIS detector set to $254 \mathrm{~nm}$ was used. The mobile phase consisted of a $50 \mathrm{mM}$ sodium phosphate (Fluka, Switzerland) buffer set to $\mathrm{pH}$ 2.8. The flow rate was $1 \mathrm{~mL} \mathrm{~min}^{-1}$ and $20 \mu \mathrm{L}$ sample was injected into the HPLC system. The peak was identified by retention time of an ascorbate standard (Sigma-Aldrich, USA). Quantification was carried by peak area.

Contents of verbascoside, isoverbascoside, and the iridoids acetylacteoside, 8-O-p-coumaroyl-harpagide, harpagoside, and pagoside were analyzed in Harpagophytum extracts on a Shimadzu HPLC system equipped with a diodearray detector according to a method slightly modified from Karioti et al. [24]. The eluent consisted of solvent $\mathrm{A}\left(\mathrm{H}_{2} \mathrm{O}\right.$ at $\mathrm{pH} 3.2$ by formic acid) and solvent B (acetonitrile). The binary gradient was as follows: $95 \%$ A (0-5 min), $85 \%$ A (5-8 min), 76\% A (8-15 min), 75\% A (15-19 min), 73\% A (19-24 min), 71\% A (24-29 min), and 50\% A (29 min). A Phenomenex Synergi 41 Hydro-RP 80A column $(250 \times$ $4.6 \mathrm{~mm}$ ) and a guard C18 precolumn were used. Evaluation of data was carried out with Shimadzu Class-VP software (version 6.13 SP2). Retention times and spectral data were obtained and compared with those of the external standards verbascoside, 8-O-p-coumaroyl-harpagide, and harpagoside. The peaks of acetylacteoside, pagoside, and isoverbascoside were verified by HPLC MS. Acetylacteoside and pagoside were quantified against harpagoside, and isoverbascoside was quantified against verbascoside. Detection was carried out at $280 \mathrm{~nm}$ with a total run time of 35 minutes. Example chromatograms of accessions are provided as Supplementary Material (Supplementary File, Figure S1, available online at http://dx.doi.org/10.1155/2016/3841803).

2.7. Collection of Venous Blood and Preparation of Neutrophils. West Midlands Research Ethics Committee in Birmingham, UK, in compliance with the Declaration of Helsinki, approved the study (Institutional Review Board approval number $10 / \mathrm{H} 1208 / 48)$. The study was based on periodontally and systemically healthy individual volunteers $(n=10$; mean age: 29 years, range 21-61 years, all female) who consented to participate in the study. Exclusion criteria included pregnancy, use of nonsteroidal anti-inflammatory drugs, mouth-washes, antimicrobial drugs, or vitamin supplements within the past three months.

Venous blood was drawn from each participant. A discontinuous Percoll gradient $(\delta=1.079: 1.098)$ was used to isolate neutrophils, followed by erythrocyte lysis using a solution containing $0.83 \% \mathrm{NH}_{4} \mathrm{Cl}, 1 \% \mathrm{KHCO}_{3}, 0.04 \%$ EDTA, and $0.25 \%$ bovine serum albumin (BSA) for 20 minutes. Isolated cells were then washed and resuspended at $1 \times$ $10^{6}$ cells $/ \mathrm{mL}$ in solution grade phosphate-buffered saline (GPBS) containing $1 \mathrm{mM}$ glucose and cations $(1 \mathrm{mM} \mathrm{MgCl}$ and $1.5 \mathrm{mM} \mathrm{CaCl}_{2}$ ). Trypan blue was used to determine cell viability and only samples with more than $98 \%$ viability were retained for further analysis.

2.8. Cell Viability Assay. Cell viability was measured using the CellTiter-Glo ${ }^{\mathrm{TM}}$ Reagent (Promega). The luciferase present in the reagent uses luciferin, oxygen, and ATP as substrates in a reaction that produces oxyluciferin and releases energy in the form of light. Because the luciferase reaction requires ATP, conditions have been created such that the amount of light produced is proportional to the amount of ATP present, reflecting the number of viable cells $[25,26] .100 \mu \mathrm{L}$ of neutrophils in GPBS $\left(1 \times 10^{5}\right.$ cells $\left./ \mathrm{mL}\right)$ and $10 \mu \mathrm{L}$ of PBS, the vehicle control, or the Harpagophytum extracts (5\%) were added to preblocked (PBS containing $1 \%$ BSA overnight, $4^{\circ} \mathrm{C}$ ) white microwells (Microlite 2, VWR, UK). The plate was placed in the microplate reader and incubated at $30^{\circ} \mathrm{C}$ for $30 \mathrm{~min}$ before the addition of $100 \mu \mathrm{L}$ of CellTiter-Glo ${ }^{\circledR}$ to each well. The contents of the wells were mixed and returned to the plate reader before reading the luminescence levels at $10 \mathrm{~min}$.

2.9. Detection of Reactive Oxygen Species (ROS) by Chemiluminescence Assay. Chemiluminescence assays were performed using luminol to detect total oxygen radical $(\mathrm{HOCl}$ and $\mathrm{H}_{2} \mathrm{O}_{2}$ ) generation (intra- and extracellular) as described in Matthews et al. [27]. All assays were performed at $37^{\circ} \mathrm{C}$ using a Berthold microplate luminometer (LB96v). Supplemented PBS (35 $\mu \mathrm{L}$, PBS supplemented with glucose, $\mathrm{Ca}^{+}$, and $\left.\mathrm{Mg}^{+}\right)$and luminol $(30 \mu \mathrm{L}, 3 \mathrm{mM})$ were added to preblocked (PBS containing $1 \% \mathrm{BSA}$ overnight, $4^{\circ} \mathrm{C}$ ) white microwells (Microlite 2, VWR, UK). The plate was then placed into the microplate reader and $100 \mu \mathrm{L}$ of the isolated neutrophils $\left(1 \times 10^{5}\right)$ was added to each well. Cells were allowed to settle for $30 \mathrm{~min}$ at $37^{\circ} \mathrm{C}$ prior to priming by addition of the extracts (only 5\%) or controls for $30 \mathrm{~min}$ at $37^{\circ} \mathrm{C}$. Neutrophils were then stimulated with either PMA (Phorbol 12-myristate 13-acetate, $25 \mathrm{nM}$ ), Fusobacterium nucleatum (MOI 1:100), opsonised S. aureus (MOI 1:300), or PBS (control). S. aureus (NCTC 6571) had been grown aerobically on mannitol salt agar and inoculated into tryptone soy broth; opsonised S. aureus was prepared according to Bergström and Åsman [28] and stored as cell suspension of $1.2 \times 10^{9}$ cells $/ \mathrm{mL}$ at $-80^{\circ} \mathrm{C}$. The anaerobic bacteria F. nucleatum (Fn; ATCC 10953) were grown at $37^{\circ} \mathrm{C}$ according to Roberts et al. [29]. The bacteria were washed three times in sterile PBS, heat-treated at $100^{\circ} \mathrm{C}$ for $10 \mathrm{~min}$, and then diluted to a suspension of $5 \times 10^{9}$ cells $/ \mathrm{mL}$ and stored at $-80^{\circ} \mathrm{C}$. PMA was 
resuspended into DMSO and diluted in PBS. For each subject, all samples were analyzed in triplicate and light emission in relative light units (RLUs) was recorded throughout the experiment.

2.10. Statistical Analysis. Based on the total of 107 polymorphic RAPD and ISSR bands, a matrix of standardized covariates was calculated for the 24 samples (6 samples investigated in this study and 18 control samples for taxonomic classification) and used as input variable in a principal component analysis (PCA) conducted with GenAlEx.

Associations between the content of chemical compounds in the six chemically analyzed samples were similarly investigated with PCA. Based on the scree-plot, three PCA components were selected for illustration of between-sample similarity. This analysis was performed using the Minitab 16 software (Minitab, State College, PA, USA).

Descriptive statistics for mean values and standard deviations were calculated on data for the enhanced chemiluminescence assays, and mean values, standardized to the total relative light units (RLUs) for each test subject, respectively, were compared using the Wilcoxon signed-rank test. SPSS 20 for Windows was used for these calculations.

\section{Results and Discussion}

3.1. Accession Identification, Diversity, and Selection. The first step in this investigation was to ascertain the taxonomic identity of the selected plant material by DNA analysis of seedlings from the field-collected seed capsules. The clustering of the 24 studied accessions in a DNA marker-based PCA (Figure 2) in general supported the morphology-based species classification. Material from six of these accessions (Table 2) was selected to determine the ability to suppress respiratory burst in human neutrophils and to investigate the antioxidant capacity and phenol content. The selected samples of $H$. procumbens ssp. transvaalense (Accession 17; O1APT) and of a putative new variety of $H$. procumbens ssp. transvaalense (Accession 3; K1APN) grouped with other $H$. procumbens accessions. Similarly, the two samples of $H$. zeyheri ssp. zeyheri (Accession 24; T1AZZ) and H. zeyheri ssp. sublobatum (Accession 14; MP3AZS), respectively, grouped with other accessions of $H$. zeyheri. One of the two samples of putative interspecific hybrids (Accession 11; MP1APH) took an intermediary position while the other sample (Accession 16 ; O1APH) showed somewhat stronger affinity to the $H$. zeyheri accessions.

3.2. Content of Total Phenols. Using the Folin-Ciocalteu assay the highest content of total phenols was found in the putative new variety of $H$. procumbens (Accession 3, $28.9 \mathrm{mg}$ GAE/g $\mathrm{dw}$ ) and in H. zeyheri ssp. sublobatum (Accession 14, $25.1 \mathrm{mg}$ GAE/g dw) whereas considerably lower content was revealed for the other samples investigated (Table 2). The external standards of harpagide, harpagoside, and verbascoside were also subjected to this analysis. Low phenolic content was identified for the iridoids and high phenolic content for the verbascoside standard (Table 2).
TABLE 2: Content of total phenols (TP) and antioxidant capacity (FRAP) of Harpagophytum extracts, presented as mean with standard deviation per dry weight ( $\mathrm{dw}$ ) of the plant material (GAE: gallic acid equivalents).

\begin{tabular}{lcccc}
\hline \multirow{2}{*}{ Accession } & \multicolumn{2}{c}{ Total phenols } & \multicolumn{2}{c}{$\mathrm{FRAP}(\mu \mathrm{mol}$} \\
& Mean & $\mathrm{SD}$ & $\mathrm{Mean}$ & $\mathrm{SD}$ \\
\hline 3 & 28.9 & 0.4 & 596.7 & 25.2 \\
11 & 13.5 & 0.6 & 204.8 & 0.1 \\
14 & 25.1 & 1.3 & 444.3 & 13.0 \\
16 & 5.1 & 0.3 & 80.8 & 13.2 \\
17 & 2.1 & 0.4 & 33.8 & 0.2 \\
24 & 3.5 & 0.5 & 54.5 & 5.6 \\
\hline Standard: harpagide & 16.7 & 1.1 & 149.2 & 0.0 \\
Standard: harpagoside & 0.0 & 0.0 & 612.3 & 3.2 \\
Standard: verbascoside & 359.9 & 9.8 & 5854.2 & 52.7 \\
\hline
\end{tabular}

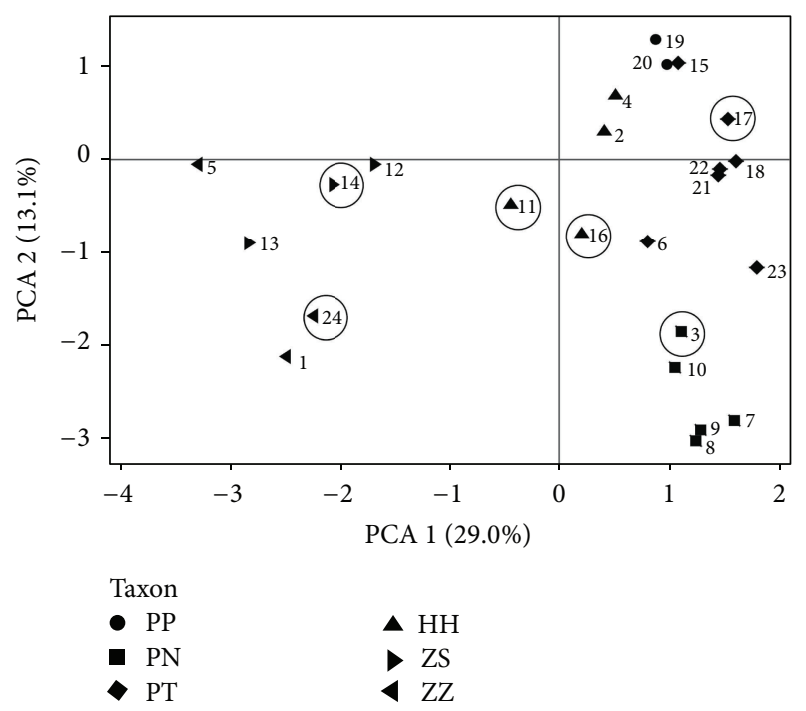

FIGURE 2: Principal component analysis showing ISSR and RAPD marker-based similarity between 24 Harpagophytum accessions used in the DNA and neutrophil study (the 6 accessions within circles). Samples are plotted on the first two components, explaining 29 and $13 \%$ of the total variation, respectively. The numbers indicate accession codes, whereas the symbols for the taxa are abbreviated as follows: PP: $H$. procumbens ssp. procumbens; PT: $H$. procumbens ssp. transvaalense; PN: putative new variety of $H$. procumbens ssp. transvaalense; ZS: H. zeyheri ssp. sublobatum; ZZ: H. zeyheri ssp. zeyheri; $\mathrm{HH}$ : putative interspecific hybrids (between $H$. procumbens and H. zeyheri).

3.3. Antioxidant Capacity of Harpagophytum Extracts: Ferric Reducing Activity of Plasma (FRAP). Using the chemical FRAP assay as a measure of antioxidant capacity, Accession 3 had the highest value $\left(596.7 \mu \mathrm{mol} \mathrm{Fe} e^{2+} / \mathrm{g} \mathrm{dw}\right)$, followed by Accession $14\left(444.3 \mu \mathrm{mol} \mathrm{Fe}{ }^{2+} / \mathrm{g} \mathrm{dw}\right)$, and more than double that of Accession $11\left(204.8 \mu \mathrm{mol} \mathrm{Fe}{ }^{2+} / \mathrm{g} \mathrm{dw}\right)$ (Table 2).

The standards harpagide, harpagoside, and verbascoside were also analyzed and verbascoside was the most potent 
TABLE 3: Composition of verbascosides and iridoids in each Harpagophytum tuber extract presented as mean value with standard deviation (SD) as mg per g dry weight of the plant material.

\begin{tabular}{lccccccccccccc}
\hline \multirow{2}{*}{ Accession } & \multicolumn{2}{c}{ Verbascoside } & \multicolumn{2}{c}{ Isoverbascoside } & \multicolumn{2}{c}{ Acetylacteoside } & \multicolumn{2}{c}{ Pagoside } & \multicolumn{3}{c}{ Harpagoside } & \multicolumn{2}{c}{ C-O-p- $\begin{array}{c}\text { Coumaroyl-harpagide } \\
\end{array}$} \\
& Mean & SD & Mean & SD & Mean & SD & Mean & SD & Mean & SD & Mean & SD \\
\hline 3 & 3.04 & 0.11 & 21.75 & 1.16 & 4.49 & 0.16 & 0.11 & 0.01 & 4.09 & 0.34 & 0.04 & 0.00 \\
11 & 1.28 & 0.11 & 6.02 & 0.50 & 3.30 & 0.45 & 0.68 & 0.08 & 9.08 & 0.97 & 4.04 & 0.41 \\
14 & 4.22 & 0.33 & 15.62 & 1.32 & 1.29 & 0.15 & 0.48 & 0.05 & 7.07 & 0.60 & 3.29 & 0.35 \\
16 & 0.64 & 0.09 & 2.47 & 0.27 & 0.84 & 0.03 & 0.17 & 0.01 & 0.96 & 0.15 & 0.07 & 0.01 \\
17 & 0.33 & 0.05 & 0.62 & 0.08 & 0.23 & 0.03 & 0.02 & 0.00 & 1.71 & 0.24 & 0.09 & 0.01 \\
24 & 0.39 & 0.08 & 0.64 & 0.14 & 0.41 & 0.11 & 0.00 & 0.00 & 0.16 & 0.01 & 0.01 & 0.00 \\
\hline
\end{tabular}

$\left(5854.2 \mu \mathrm{mol} \mathrm{Fe} e^{2+} / \mathrm{g} \mathrm{dw}\right)$ with approximately $10 \times$ the capacity of harpagoside and $40 \times$ the capacity of harpagide (Table 2 ).

Thus, there was a very large difference among samples in antioxidant capacity and also the antioxidant capacity of the different standards varied largely.

3.4. Content of Verbascoside, Isoverbascoside, Iridoids, and Ascorbate. The content of verbascoside was highest in Accession 14 (mean $4.2 \mathrm{mg} / \mathrm{g} \mathrm{dw}$ ) followed by Accession 3 (mean $3.0 \mathrm{mg} / \mathrm{g} \mathrm{dw}$ ) (Table 3). The content of isoverbascoside was highest in Accession 3 (mean $21.8 \mathrm{mg} / \mathrm{g} \mathrm{dw}$ ). Significant amounts of harpagoside and 8-O-p-coumaroyl harpagide were identified in Accession 11 as well as in Accession 14 (Table 3). The extracts from Accessions 16, 17, and 24 contained low levels of verbascoside, isoverbascoside, and iridoid compounds. HPLC analysis revealed that there was no ascorbate in the samples (Supplementary File, Figure S2).

Thus, the phytochemical analysis revealed substantial differences in chemical composition between the analyzed taxa but whether these differences are taxon-specific must be ascertained in future studies using a much larger material with several samples of each taxon.

3.5. Cell Viability Assay. There were no significant differences among the effects of different extracts on neutrophil cell viability, and none of the extracts showed lethal/suppressive effects on neutrophils (Supplementary File, Figure S3).

3.6. Effect on Neutrophil Reactive Oxygen Species (ROS) Production. To assess the effects of the extracts on neutrophil ROS production, neutrophils from healthy volunteers were preincubated with extracts (5\% solutions, including $2.5 \%$ ethanol) or controls (PBS or vehicle control 2.5\% ethanol) for $30 \mathrm{~min}$ prior to stimulation.

For unstimulated cells (PBS, Figure 3(a)), there were significant differences in response among some of the samples. Accession 3 responded significantly stronger (lower RLUs recorded) than Accessions $16(p=0.028)$ and $24(p=0.037)$, and Accession 14 was significantly stronger than Accessions $16(p=0.022), 17(p=0.028)$, and $24(p=0.047)$ in protecting the cells. However, none of the samples were significantly different from the PBS or vehicle ethanol control.

For stimulated cells, Staphylococcus aureus treatment (Figure 3(b)), there was a significant proinflammatory effect of Accession 11 in comparison to Accession $16(p=0.028)$. A significant proinflammatory response was also detected for Accession 14 with regard to Accession 17 ( $p=0.017$ ). However, none of the samples were significantly different from the PBS or vehicle ethanol control.

With the Toll-like receptor ligand F. nucleatum treatment (Figure 3(c)), a significant proinflammatory response was detected for Accession 11 in comparison with the vehicle control $(p=0.037)$ and also in comparison with Accession $17(p=0.017)$.

With PMA treatment (Figure 3(d)), Accessions 14, 16, and 17 showed significant anti-inflammatory activity in comparison to the PBS control ( $p=0.038, p=0.028$, and $p=0.049$ ) but no significant difference was detected in comparison with the vehicle control. There was also a significant difference in anti-inflammatory effects among samples. Accessions 14 $(p=0.029)$ and $17(p=0.037)$ had significantly higher activity than Accession 3, and Accessions $14(p=0.015)$ and 17 ( $p=0.031)$ had significantly higher activity than Accession 11.

Neutrophils were also preincubated with standard solutions $(0.5 \mu \mathrm{g} / \mathrm{mL}$ verbascoside and $0.5 \mu \mathrm{g} / \mathrm{mL}$ harpagoside). For unstimulated cells (PBS, Figure 4(a)), significant effects against ROS production were observed for harpagoside and verbascoside in comparison to PBS control $(p=0.043$ and $p=0.043$, resp.). Verbascoside was also significantly different to the vehicle control $(p=0.043)$ and to harpagoside $(p=0.043)$. For stimulated cells, Staphylococcus aureus and $F$. nucleatum treatments only identified a significant difference between PBS and vehicle control ( $p=0.043)$. PMA treatment (Figure 4(b)) revealed a significant difference between PBS and vehicle control $(p=0.043)$ and also between verbascoside and PBS control and harpagoside ( $p=$ 0.043 and $p=0.043$, resp.).

Accessions 3 and 14 contained highest levels of verbascoside and isoverbascoside. Accession 11 contained the highest levels of harpagoside, pagoside, and 8-O-p-coumaroylharpagide. Ouitas and Heard [30] have previously examined 


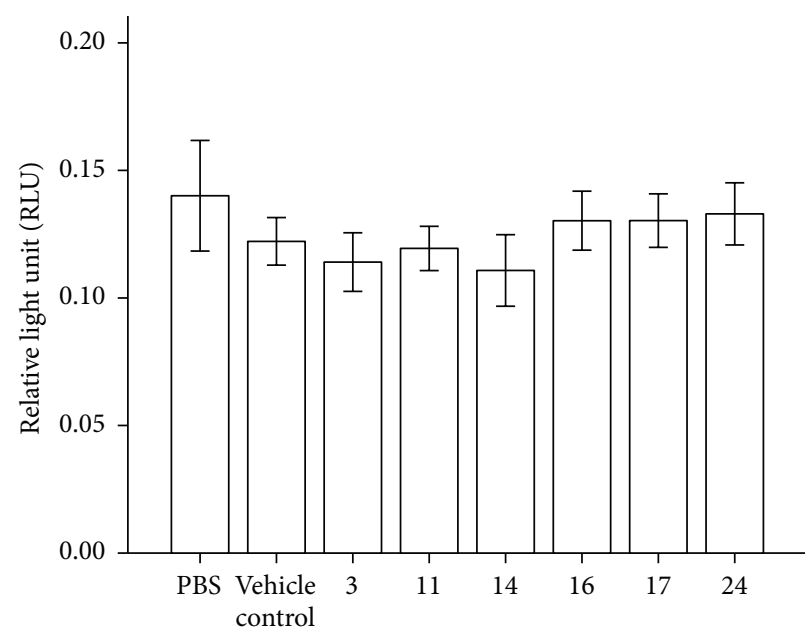

(a)

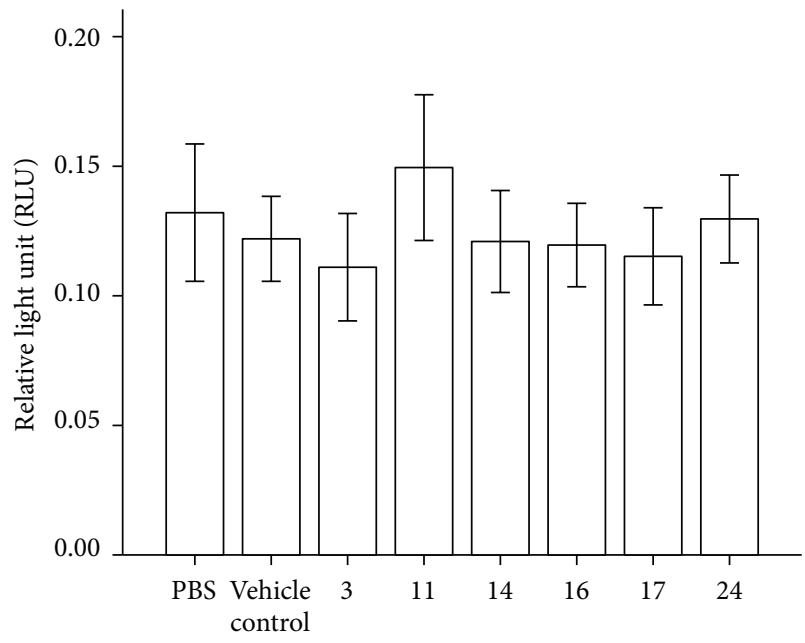

(c)

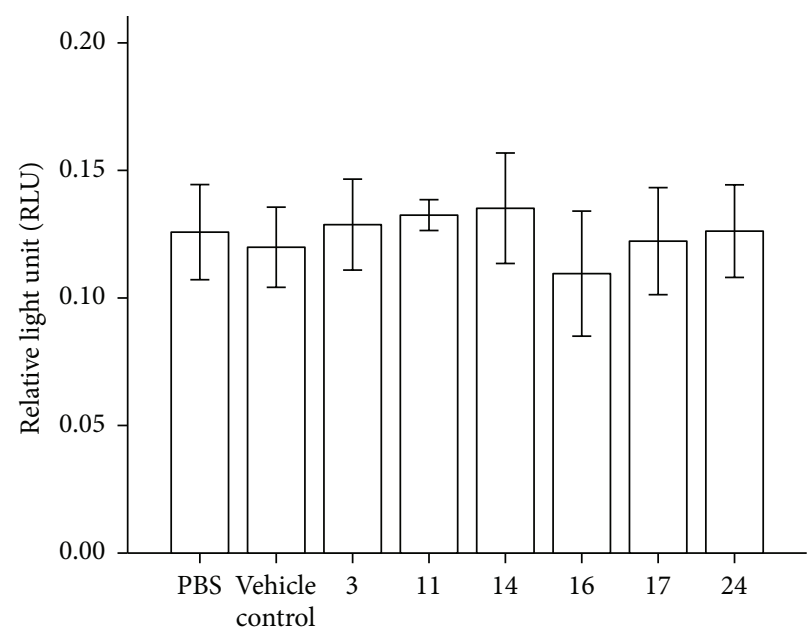

(b)

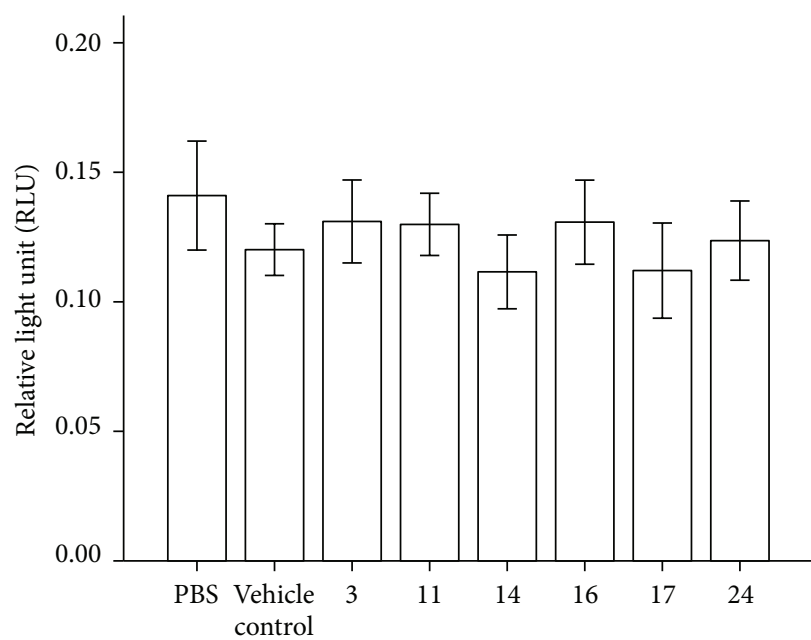

(d)

FIGURE 3: Luminol-detected total ROS production by neutrophils stimulated with (a) PBS (no stimulus), (b) opsonised Staphylococcus aureus, (c) Fusobacterium nucleatum, and (d) PMA (25 nM) in the presence of PBS, ethanol, and Accessions 3, 11, 14, 16, 17, and 24 ( $n=10)$. Error bars: $95 \%$ CI. All sample results were compared by Wilcoxon two related samples tests.

a number of $H$. procumbens extracts for anti-inflammatory activity and, in broad agreement with our study, have shown some proinflammatory responses. The reported antiinflammatory effect by Qi et al. [31] was not replicated in our report, which may be due to cell specific responses and/or the differing properties of the various compounds available in the extracts. In a previous study by Matthews et al. [18] it was demonstrated that ascorbate may significantly decrease the amount of ROS produced by healthy neutrophils stimulated by PMA; however ascorbate was not detected in our samples. Ethanol is known to decrease ROS production by neutrophils [32] and can increase superoxide production during PMA treatment of neutrophils [33]. In our studies the PMA-mediated respiratory burst was clearly affected by ethanol as shown by the vehicle control.

Bivariate Pearson rank correlation analysis identified significant correlations between total phenols and FRAP $(R=$
0.991, $p=0.000$ ) as well as between total phenols, FRAP, and PBS control (luminol-detected total ROS production) with verbascoside $(R=0.934, p=0.006 ; R=0.903, p=0.014$; $R=-0.931, p=0.007)$ and with isoverbascoside $(R=0.985$, $p=0.000 ; R=0.999, p=0.000 ; R=-0.846, p=0.034$ ). We also noted significant correlation between total phenols and FRAP with PBS control (luminol-detected total ROS production) $(R=-0.888, p=0.018 ; R=-0.847, p=$ $0.033)$. The high positive correlations between the content of total phenols and verbascoside as well as with isoverbascoside and the high negative correlation between total phenols and FRAP as well as with the PBS control show that verbascoside really is an important antioxidant phenol in Harpagophytum and verifies the antioxidant activity of samples as revealed in the unstimulated cell PBS control treatment.

The present pilot study revealed a tentative antiinflammatory effect of three Harpagophytum taxa using a 


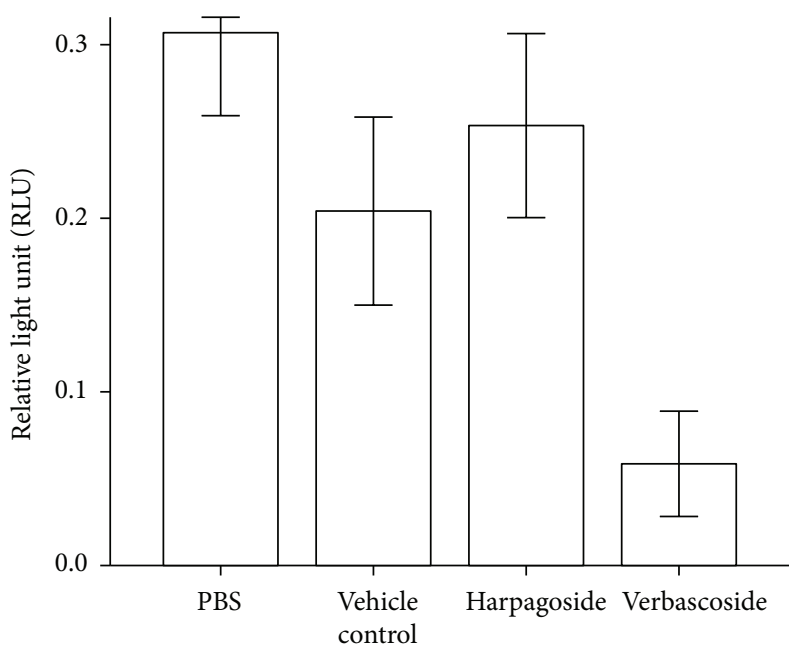

(a)

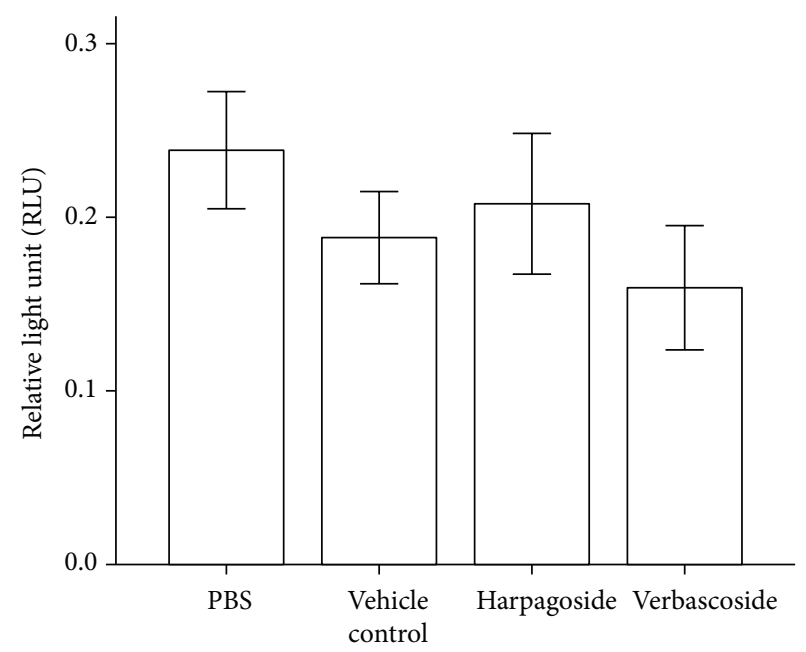

(b)

FIGURE 4: Luminol-detected total ROS production by neutrophils stimulated with (a) PBS or (b) PMA (25 nM) in the presence of PBS, ethanol, harpagoside $(0.5 \mu \mathrm{g} / \mathrm{mL})$, and verbascoside $(0.5 \mu \mathrm{g} / \mathrm{mL})(n=5)$. Error bars: $95 \%$ CI. All sample results were compared by Wilcoxon two related samples tests.

modest number of subjects. Future verifying studies using a larger number of subjects should take into account gender and age of volunteers, as well as the impact of single purified constituents of the extracts on respiratory burst process in vitro.

\section{Conclusions}

The accessions of different Harpagophytum taxa were shown to be biochemically very variable with regard to content of verbascoside, isoverbascoside, and analyzed iridoids, and some accessions had very high antioxidant capacity. However, we were unable to corroborate a general anti-inflammatory effect for $H$. procumbens with the neutrophil model although evidence of anti-inflammatory activity was noticed for three taxa. In addition, the proinflammatory effect noticed for one taxon needs further verification.

\section{Competing Interests}

The authors declare no competing interests.

\section{Authors' Contributions}

All authors have contributed to the intellectual content of this paper following these requirements: (1) significant contributions to the conception and design, acquisition of data or analysis, and interpretation of data; (2) drafting or revising the paper for intellectual content; and (3) final approval of the published paper.

\section{Acknowledgments}

This study was funded by the NORDIC-SADC Plant Genetic Resources Centre, Lusaka, Zambia.

\section{References}

[1] H. D. Ihlenfeldt and H. Hartmann, "Die gattung Harpagophytum (Burch.) DC. Ex Meissn. (Monographie der afrikanischen Pedaliaceae II)," Mitteilungen aus dem Institut für Allgemeine Botanik Hamburg, vol. 13, pp. 16-69, 1970.

[2] D. W. Lim, J. G. Kim, D. Han, and Y. T. Kim, "Analgesic effect of Harpagophytum procumbens on postoperative and neuropathic pain in rats," Molecules, vol. 19, no. 1, pp. 1060-1068, 2014.

[3] D. Loew, J. Möllerfeld, A. Schrödter, S. Puttkammer, and M. Kaszkin, "Investigations on the pharmacokinetic properties of Harpagophytum extracts and their effects on eicosanoid biosynthesis in vitro and ex vivo," Clinical Pharmacology and Therapeutics, vol. 69, no. 5, pp. 356-364, 2001.

[4] B. Baghdikian, M. C. Lanhers, J. Fleurentin et al., "An analytical study, anti-inflammatory and analgesic effects of Harpagophytum procumbens and Harpagophytum zeyheri," Planta Medica, vol. 63, no. 2, pp. 171-176, 1997.

[5] R. Grahame and B. V. Robinson, "Devil's claw (Harpagophytum procumbens): pharmacological and clinical studies," Annals of the Rheumatic Diseases, vol. 40, no. 6, p. 632, 1981.

[6] L. W. Whitehouse, M. Znamirowska, and C. J. Paul, "Devil's claw (Harpagophytum procumbens): no evidence for antiinflammatory activity in the treatment of arthritic disease," Canadian Medical Association Journal, vol. 129, no. 3, pp. 249251, 1983.

[7] "Harpagophytum procumbens (devil's claw). Monograph," Alternative Medicine Review, vol. 13, no. 3, pp. 248-252, 2008.

[8] J. Qi, J.-J. Chen, Z.-H. Cheng, J.-H. Zhou, B.-Y. Yu, and S. X. Qiu, "Iridoid glycosides from Harpagophytum procumbens D.C. (devil's claw)," Phytochemistry, vol. 67, no. 13, pp. 1372-1377, 2006.

[9] N. Abdelouahab and C. Heard, "Effect of the major glycosides of Harpagophytum procumbens (Devil's Claw) on epidermal cyclooxygenase-2 (COX-2) in vitro," Journal of Natural Products, vol. 71, no. 5, pp. 746-749, 2008.

[10] T. H. Huang, V. H. Tran, R. K. Duke et al., "Harpagoside suppresses lipopolysaccharide-induced iNOS and COX-2 
expression through inhibition of NF- $\kappa \mathrm{B}$ activation," Journal of Ethnopharmacology, vol. 104, no. 1-2, pp. 149-155, 2006.

[11] M. Kaszkin, K. F. Beck, E. Koch et al., "Downregulation of inos expression in rat mesangial cells by special extracts of Harpagophytum procumbens derives from harpagoside-dependent and independent effects," Phytomedicine, vol. 11, no. 7-8, pp. 585595, 2004.

[12] F. Morel, J. Doussiere, and P. V. Vignais, "The superoxidegenerating oxidase of phagocytic cells. Physiological, molecular and pathological aspects," European Journal of Biochemistry, vol. 201, no. 3, pp. 523-546, 1991.

[13] A. Noguera, S. Batle, C. Miralles et al., "Enhanced neutrophil response in chronic obstructive pulmonary disease," Thorax, vol. 56, no. 6, pp. 432-437, 2001.

[14] Y. Zhang, G. L. Mills, and M. G. Nair, "Cyclooxygenase inhibitory and antioxidant compounds from the mycelia of the edible mushroom Grifola frondosa," Journal of Agricultural and Food Chemistry, vol. 50, no. 26, pp. 7581-7585, 2002.

[15] H. Higuchi, M. Ishizaka, and H. Nagahata, "Complement receptor type 3 (CR3)- and $\mathrm{Fc}$ receptor (FCR)-mediated matrix metalloproteinase 9 (MMP-9) secretion and their intracellular signalling of bovine neutrophils," Veterinary Research Communications, vol. 31, no. 8, pp. 985-991, 2007.

[16] L. C. Parker, M. K. B. Whyte, S. K. Dower, and I. Sabroe, "The expression and roles of toll-like receptors in the biology of the human neutrophil," Journal of Leukocyte Biology, vol. 77, no. 6, pp. 886-892, 2005.

[17] H. Higuchi and H. Nagahata, "Comparison of superoxide production, protein kinase $\mathrm{C}$ and tyrosine kinase activities in neutrophils from neonatal calves and cows," Research in Veterinary Science, vol. 65, no. 2, pp. 139-143, 1998.

[18] J. B. Matthews, H. J. Wright, A. Roberts, P. R. Cooper, and I. L. Chapple, "Hyperactivity and reactivity of peripheral blood neutrophils in chronic periodontitis," Clinical and Experimental Immunology, vol. 147, no. 2, pp. 255-264, 2007.

[19] M. Muzila, G. Werlemark, R. Ortiz et al., "Assessment of diversity in Harpagophytum with RAPD and ISSR markers provides evidence of introgression," Hereditas, vol. 151, no. 4-5, pp. 91-101, 2014.

[20] M. Muzila, M. P. Setshogo, and S. W. Mpoloka, "Multivariate analysis of Harpagophytum DC. Ex meisn (Pedaliaceae) based on fruit characters," International Journal of Biodiversity and Conservation, vol. 3, no. 3, pp. 101-109, 2011.

[21] V. L. Singleton, R. Orthofer, and R. M. Lamuela-Raventós, "Analysis of total phenols and other oxidation substrates and antioxidants by means of folin-ciocalteu reagent," Methods in Enzymology, vol. 299, pp. 152-178, 1999.

[22] I. F. F. Benzie and J. J. Strain, "The ferric reducing ability of plasma (FRAP) as a measure of "antioxidant power": the FRAP assay," Analytical Biochemistry, vol. 239, no. 1, pp. 70-76, 1996.

[23] A. Medina-Remón, A. Barrionuevo-González, R. Zamora-Ros et al., "Rapid Folin-Ciocalteu method using microtiter 96-well plate cartridges for solid phase extraction to assess urinary total phenolic compounds, as a biomarker of total polyphenols intake," Analytica Chimica Acta, vol. 634, no. 1, pp. 54-60, 2009.

[24] A. Karioti, E. Fani, F. F. Vincieri, and A. R. Bilia, "Analysis and stability of the constituents of Curcuma longa and Harpagophytum procumbens tinctures by HPLC-DAD and HPLC-ESI-MS," Journal of Pharmaceutical and Biomedical Analysis, vol. 55, no. 3, pp. 479-486, 2011.

[25] B. Ekwall, B. Ekwall, and M. Sjöström, "MEIC evaluation of acute systemic toxicity. Part VIII. Multivariate partial least squares evaluation, including the selection of a battery of cell line tests with a good prediction of human acute lethal peak blood concentration for 50 chemicals," ATLA, vol. 28, pp. 201234, 2000.

[26] N. Sussman, M. Waltersheid, T. Butler, J. Kelly, J. Cali, and T. Riss, "The predictive nature of high-throughput toxicity screening; utilizing a human liver cell line, esearchers are able to identify toxic antihistamines," Drug Discovery and Development, vol. 5, pp. 71-72, 2002.

[27] J. B. Matthews, H. J. Wright, A. Roberts, N. Ling-Mountford, P. R. Cooper, and I. L. C. Chapple, "Neutrophil hyperresponsiveness in periodontitis," Journal of Dental Research, vol. 86, no. 8, pp. 718-722, 2007.

[28] K. Bergström and B. Åsman, "Luminol enhanced fc-receptor dependent chemiluminescence from peripheral PMN cells. A methodological study," Scandinavian Journal of Clinical and Laboratory Investigation, vol. 53, no. 2, pp. 171-177, 1993.

[29] A. Roberts, J. B. Matthews, S. S. Socransky, P. P. E. Freestone, P. H. Williams, and I. L. C. Chapple, "Stress and the periodontal diseases: effects of catecholamines on the growth of periodontal bacteria in vitro," Oral Microbiology and Immunology, vol. 17, no. 5, pp. 296-303, 2002.

[30] N. A. Ouitas and C. Heard, "Estimation of the relative antiinflammatory efficacies of six commercial preparations of Harpagophytum procumbens (Devil's Claw)," Phytotherapy Research, vol. 24, no. 3, pp. 333-338, 2010.

[31] J. Qi, N. Li, J.-H. Zhou, B.-Y. Yu, and S. X. Qiu, "Isolation and anti-inflammatory activity evaluation of triterpenoids and a monoterpenoid glycoside from Harpagophytum procumbens," Planta Medica, vol. 76, no. 16, pp. 1892-1896, 2010.

[32] M. Patel, A. Keshavarzian, V. Kottapalli, B. Badie, D. Winship, and J. Z. Fields, "Human neutrophil functions are inhibited in vitro by clinically relevant ethanol concentrations," Alcoholism: Clinical and Experimental Research, vol. 20, no. 2, pp. 275-283, 1996.

[33] K. Raddassi and J. J. Murray, "Ethanol increases superoxide anion production stimulated with $4 \beta$ - phorbol 12 -myristate 13 acetate in human polymorphonuclear leukocytes involvement of protein kinase C," European Journal of Biochemistry, vol. 267, no. 3, pp. 720-727, 2000. 


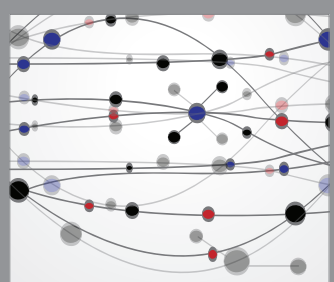

The Scientific World Journal
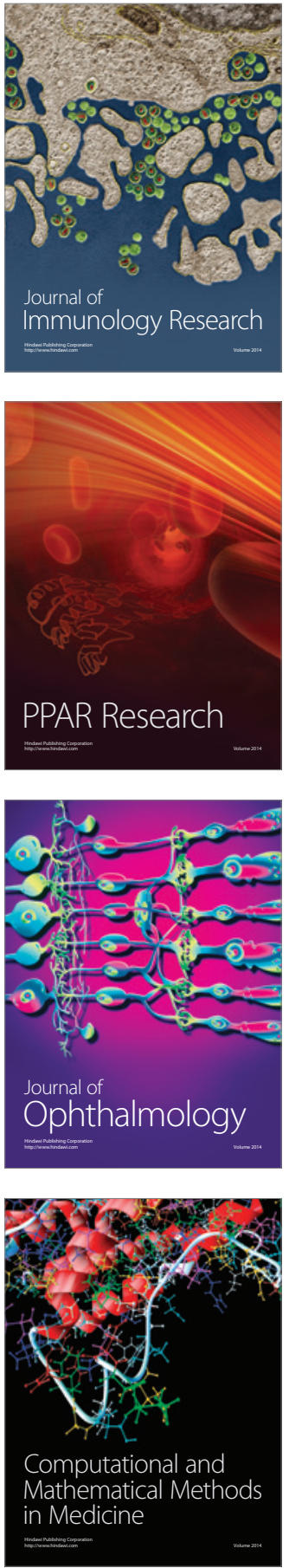

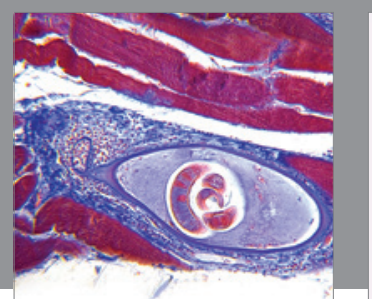

Gastroenterology Research and Practice

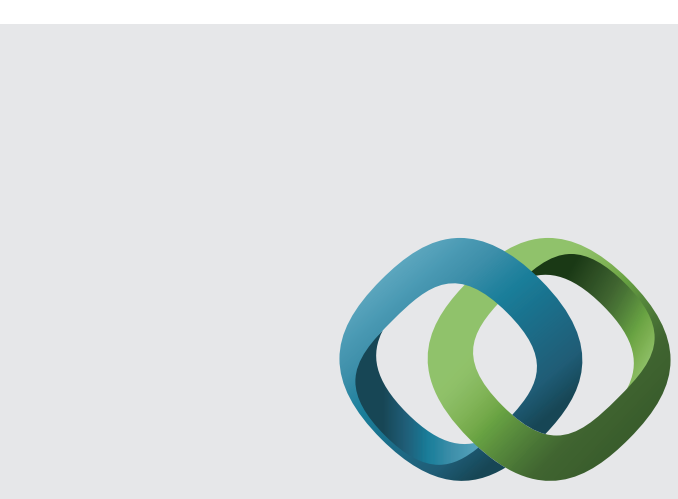

\section{Hindawi}

Submit your manuscripts at

http://www.hindawi.com
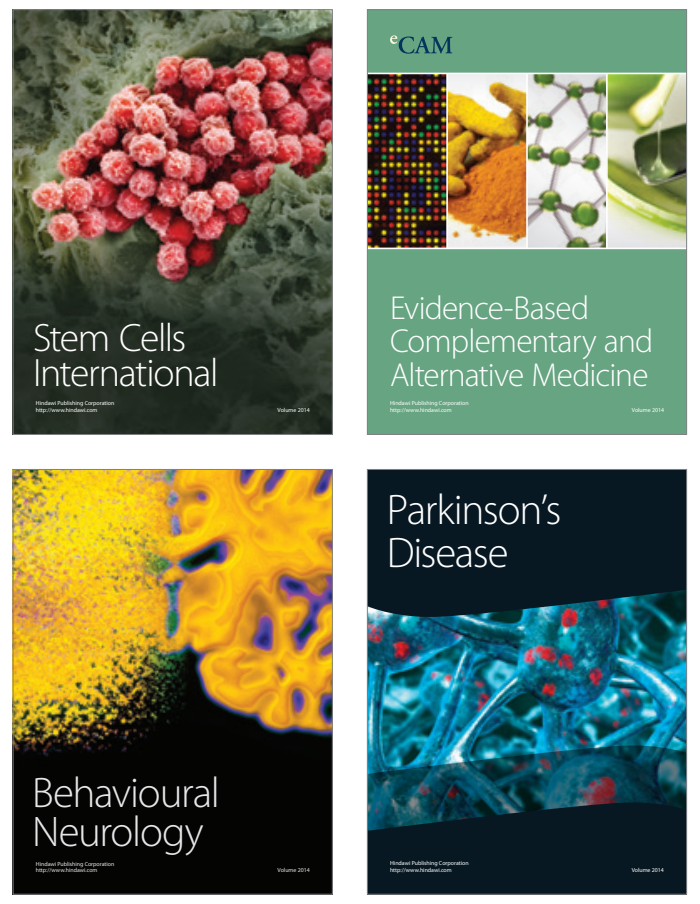
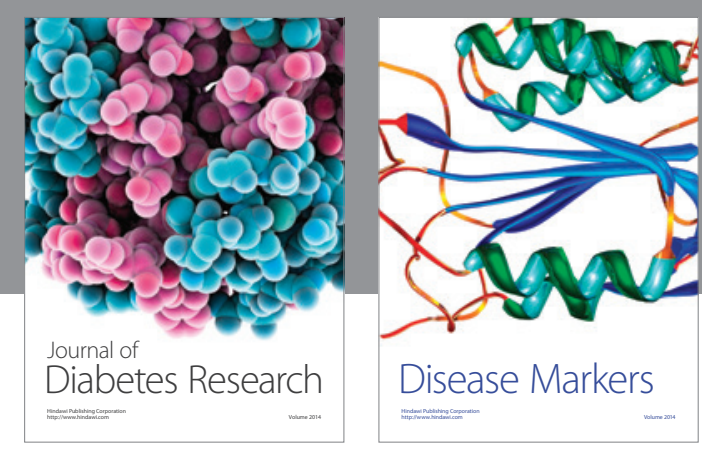

Disease Markers
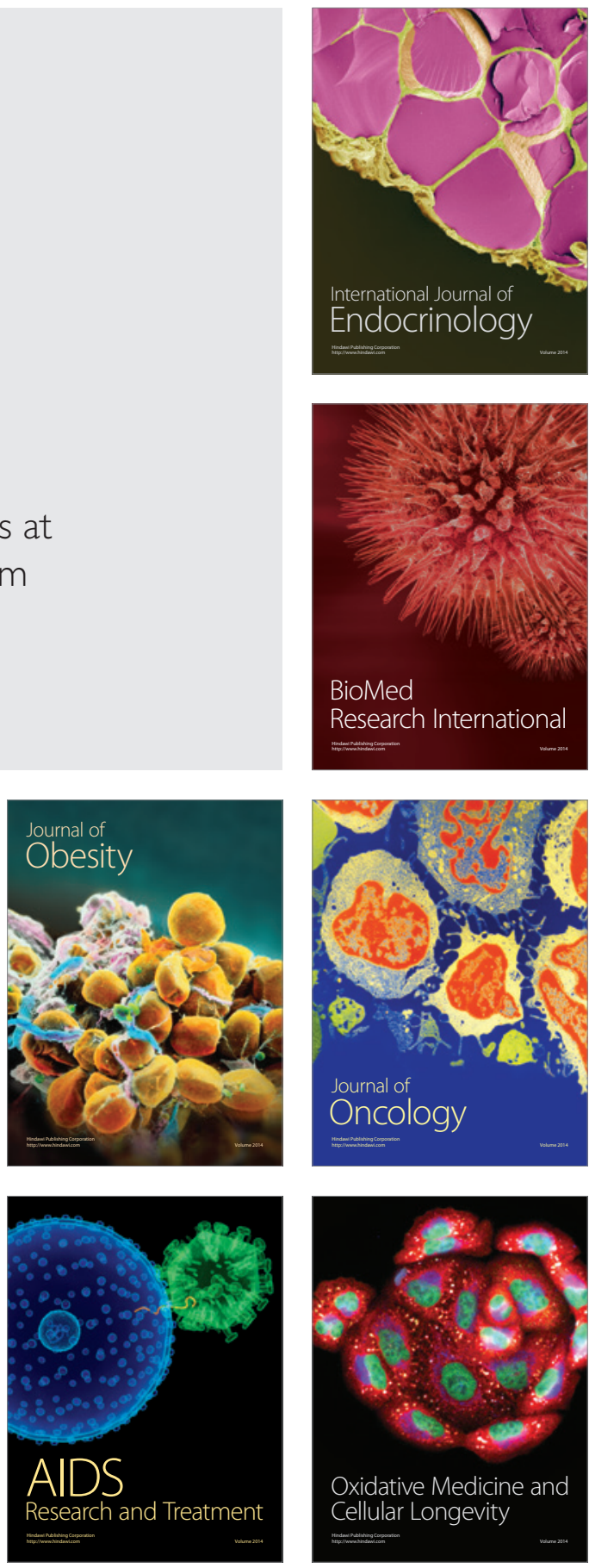